\title{
MERS-CoV transmitted from animal-to-human vs MERS- CoV transmitted from human-to-human: Comparison of virulence and therapeutic outcomes in a Saudi hospital
}

\author{
Saad Alhumaid ${ }^{1 \star}$, Mansour Tobaiqy ${ }^{2}$, Mohamoud Albagshi ${ }^{3}$, Ahmed Alrubaya ${ }^{4}$, \\ Fahad Algharib ${ }^{5}$, Ahmed Aldera ${ }^{6}$, Jalal Alali ${ }^{7}$ \\ ${ }^{1}$ Drug Information and Research Department, Administration of Pharmaceutical Care, Ministry of Health, Al-Ahsa, ${ }^{2}$ Department \\ of Pharmacology, Faculty of Medicine, University of Jeddah, Jeddah, ${ }^{3}$ Respiratory Care Department, ${ }^{4}$ Employees Affairs Clinic, \\ King Fahad Hofuf Hospital, ${ }^{5}$ Health Affairs for Assisted Medical Services, ${ }^{6}$ Pharmacy Department, Prince Saud Bin Jalawi \\ Hospital, ${ }^{7}$ Internal Medicine Department, King Fahad Hofuf Hospital, Ministry of Health, Al-Ahsa, Saudi Arabia
}

*For correspondence: Email: saalhumaid@moh.gov.sa

\begin{abstract}
Purpose: To examine virulence (severity of disease and/or symptoms) and response to therapy (medications, supportive measures) between confirmed cases of MERS-CoV animal-to-human transmission compared with cases resulting from human-to-human transmission.

Methods: The records for laboratory-confirmed MERS-CoV infections that were diagnosed at King Fahad Hofuf Hospital (Al-Ahsa, Saudi Arabia) from April 1, 2012 to November 30, 2016 were reviewed retrospectively.

Results: There were 107 laboratory-confirmed MERS-CoV cases. Transmission of the virus from animal-to-human was less common (21.4 vs $78.6 \%$ ). The human-to-human transmission group had a higher mortality rate (53.57 vs $39.13 \%$ ). Patients in this group also had higher APACHEE II (11.2 vs 23 , $p=0.043$ ), SOFA scores (10.9 vs $12.55, p=0.076)$, and higher rates of sepsis (17.39 vs $26.19 \%, p=$ $0.582)$ and septic shock (13.04 vs $20.23 \%, p=0.555)$. The infections were more severe in the humanto-human transmission group; patients had increased rates of intensive care unit (ICU) admission (43.47 vs $51.19 \%)$, decreased time from symptom onset until ICU admission, and greater need for mechanical ventilation ( 8 days vs 4 days, $p=0.041$, and 6 days vs 4 days, respectively), longer time to respond to antiviral treatment and resolve the infection ( 5 days vs 11 days and 7 days vs 13 days, respectively) and a shorter time from the beginning of symptoms until death (11 days vs 5 days, $p=$ 0.048).
\end{abstract}

Conclusion: MERS-CoV transmitted from human-to-human was more virulent, resulted in higher casemortality rates and required more ICU treatment.

Keywords: Animal-to-human, Human-to-human, MERS-CoV, Outcomes, Primary infection, Secondary infection, Virulence

This is an Open Access article that uses a funding model which does not charge readers or their institutions for access and distributed under the terms of the Creative Commons Attribution License (http://creativecommons.org/licenses/by/4.0) and the Budapest Open Access Initiative (http://www.budapestopenaccessinitiative.org/read), which permit unrestricted use, distribution, and reproduction in any medium, provided the original work is properly credited.

Tropical Journal of Pharmaceutical Research is indexed by Science Citation Index (SciSearch), Scopus, International Pharmaceutical Abstract, Chemical Abstracts, Embase, Index Copernicus, EBSCO, African Index Medicus, JournalSeek, Journal Citation Reports/Science Edition, Directory of Open Access Journals (DOAJ), African Journal Online, Bioline International, Open-J-Gate and Pharmacy Abstracts 


\section{INTRODUCTION}

Infection with Middle East Respiratory Syndrome Coronavirus (MERS-CoV) was diagnosed first in patients from the Kingdom of Saudi Arabia (KSA) in April 2012. [1]. MERS-CoV infection also has been diagnosed in individuals from at least 26 other countries who visited the Middle East, but most reported cases of the infection have been in residents of the KSA [2].

As of early December 2015, 549 of 1,277 (43\%) patients with a laboratory-confirmed infection died from the disease, according to the KSA Ministry of Health (MoH) [3]. MERS-CoV infection occurs via animal-to-human transmission (primary infection) or human-tohuman transmission (secondary infection) of this virus [4,5]. Therefore, this zoonotic virus can therefore also be transmitted among individuals as a secondary infection [6-8]. In humans, direct or indirect contact with an infected camel is the number one source of MERS-CoV infection $[7,8]$. Lack of adherence to infection control and prevention measures has resulted in infections in groups of individuals who are in close contact and in healthcare settings [5,9]. This evidence supports the theory of human-to-human transmission. However, most reported cases of human-to-human transmission are from healthcare, not household, settings. No transmission at the community level of MERSCoV has yet been detected.

The objective of this study is to compare the virulence (severity of disease and/or symptoms) and response to therapy (medications and supportive measures) between confirmed MERS$\mathrm{CoV}$ cases transmitted via animal-to-human contact and the confirmed MERS-CoV cases transmitted via human-to-human contact. Differences in virulence (disease severity and/or symptoms) were examined utilizing the Acute Physiology and Chronic Health Evaluation II (APACHE II), as well as the Sequential Organ Failure Assessment (SOFA) scoring systems. Differences in responses to therapy (various medications and supportive measures) were evaluated using records of clinical variables, laboratory test results, and final patient outcomes (i.e., recovered, transferred, died, or discharged).

\section{METHODS}

\section{Study setting and design}

Al-Ahsa Governate in the Al-Ahsa oasis region in Eastern Saudi Arabia is the largest governate in the Eastern Province. This region governs both urban and rural populations totalling 1.3 million people. Ministry of Health $(\mathrm{MoH})$ is the main public institution that provides preventive, curative, and rehabilitative healthcare services for the entire population of the Al-Ahsa region. $\mathrm{MoH}$ is responsible for the management, planning, financing, and regulation of the healthcare sector through primary healthcare centres, generalized and specialized hospitals, and overall supervision of private healthcare facilities. When a report of a suspected case of MERS is generated at a primary healthcare center, the patient is referred to a secondary or tertiary care hospital and the relevant health directorates of $\mathrm{MoH}$ are notified. King Fahad Hofuf Hospital is a 500-bed general hospital in Hofuf. It is the biggest hospital in the city area in Al-Ahsa. The hospital records of patients with laboratory-confirmed MERS-CoV infection treated at King Fahad Hofuf Hospital (Al-Ahsa, Saudi Arabia) between April 1, 2012, and November 30, 2016, were reviewed retrospectively.

\section{Definitions}

In addition to the requirement of a laboratoryconfirmed diagnosis of infection with MERS-CoV, the MERS case definition used for this study included presence of one or more symptoms and clinical signs of acute respiratory infection, fever $\geq 38{ }^{\circ} \mathrm{C}$, cough, shortness of breath with evidence of pneumonia on radiographic images, and other clinical or radiological evidence of pneumonia [10]. Pneumonia was defined as any new, unexplained, lower respiratory tract symptoms (e.g., cough, dyspnea) with one or more systemic clinical signs (e.g., fever or shivering), a new focal chest sign on examination, and thoracic radiographic images with new or progressive pulmonary infiltration [12].

The definition of animal-to-human (primary infection) MER-CoV infection required exposure to a dromedary camel (the primary animal host for MERS-CoV) within fourteen days [10] before the start of symptoms, and a laboratoryconfirmed diagnosis of MERS. Visiting market environments, camel pens, farms, and barn areas where dromedary camels are present increases the risk of a primary MERS-CoV infection [11]. Consumption of raw camel urine or milk, meat not thoroughly cooked, or food contaminated with animal secretions or products also increases the risk of infection.

The definition of human-to-human transmission (secondary infection) required close contact with an infected individual at least fourteen days prior to the start of symptoms [11]. Close contact was 
determined to be less than 2 meters away from an infected person or being in the room or care area for a prolonged period without personal protective equipment (i.e., gloves, gown, respirator, eye protection), having direct contact with human secretions (e.g., sputum during a cough) without personal protective equipment, or both [13].

MERS-CoV infection was recorded as healthcare-associated if illness onset was greater than 48 hours after hospital admission or within fourteen days after discharge from healthcare facility with recorded cases of MERS-CoV infection [11]. Any viral, bacterial, or fungal infections that occurred within fourteen days of a MERS-CoV diagnosis were recorded as concomitant infections [11].

\section{Data collection and sample selection}

Data were collected pertaining to demographic, clinical, laboratory, and treatment outcomes. This descriptive study was performed at the Department of Pulmonology, Directorate of Health Affairs, Al-Ahsa, KSA. Primary data were collected from all confirmed cases that were reported between April 1, 2012 and November 30,2016 by public and private hospitals serving the Al-Ahsa region. The data were compiled in Al-Ahsa for retrospective review and analysis.

The data were collected from several sources, including the patients' medical files, the preventive medicine database, and the records of infection control outbreak investigations. Data collection included information from the point of patient admission and continued until the date of discharge from the hospital or the date of death. Information on missing data was obtained and clarification of data was performed by contacting the attending physicians and other healthcare providers. No exclusion criteria were applied to laboratory-confirmed MERS-CoV cases.

A preformed Excel data sheet listing the demographic, clinical, and laboratory variables, and treatment outcomes, was used for the data reporting. The variables for which data were collected included patients' information (i.e., patient's initials and medical record number, sex, age, weight, body mass index, nationality, residence, level of education, occupation, residence, and use of tobacco), mode of MERSCoV transmission (i.e., animal-to-human or human-to-human), co-morbid conditions, complications related to MERS-CoV infection, time of symptom onset, clinical symptoms, laboratory abnormalities, medications, and supportive measures offered to the patient and treatment outcomes (i.e., recovered, transferred, died, or discharged).

Both the SOFA and APACHE II scoring systems were utilized in order to estimate virulence (severity of disease or symptoms, or both). Information on all required physiological parameters was collected during the first 24 hours within the ICU (i.e., temperature, Glasgow Coma Score, mean arterial pressure, heart rate, respiratory rate, $\mathrm{FiO}_{2}$ and $\mathrm{PaO}_{2}$, arterial $\mathrm{pH}$, mechanical ventilation, use of vasopressors, serum sodium, serum potassium, creatinine, bilirubin, hematocrit, platelet count, white blood cell count, and urine output).

\section{Data management and analysis}

The descriptive statistics used depended on whether a variable was continuous or categorical. Chi-square or Fisher's exact tests were utilized in order to analyse the data for categorical variables. The Student's t-test was used to analyse data for continuous variables. Two tailed $p$-values were used; a p-value $<0.05$ indicated statistically significant results. Microsoft Excel 2013 (Microsoft Corporation, Redmond, USA) and IBM SPSS Statistics software (version 23.0, IBM Corporation, Armonk, NY, USA) were used for the statistical analysis.

\section{Ethical approval}

We obtained approval for the study from the General Administration of Research and Studies Committee at the Ministry of Health (approval no. 2273229 dated 25 May 2016) and King Fahad Medical City (KACST, KSA: H-01-R-012). The guidelines of the Declaration of Helsinki were followed for the study [14].

\section{RESULTS}

From April 1, 2012, to November 30, 2016, there were 107 laboratory-confirmed MERS-CoV cases at King Fahad Hofuf Hospital. Of those patients with MERS-CoV infection, 23 (21.4\%) cases were transmitted from animal-to-human while 84 (78.6 \%) were transmitted from humanto-human.

The results for the baseline characteristics, comorbidities, symptoms, laboratory findings and screening for microbial coinfections and use of antibacterials and antiviral agents, complications related to MERS-CoV infection, MERS-CoV infection severities, and treatment outcomes for all the confirmed cases, based on mode of virus transmission, are presented in Tables 1-4. 
Table 1: Patient demographics of confirmed MERS-CoV cases based on mode of virus transmission

\begin{tabular}{|c|c|c|c|}
\hline Variable & $\begin{array}{l}\text { Animal-to-human group } \\
\text { (primary infection) }(n=23)\end{array}$ & $\begin{array}{c}\text { Human-to-human group } \\
\text { (secondary infection) }(n=84)\end{array}$ & $P$-value \\
\hline \multicolumn{4}{|l|}{ Demographics } \\
\hline Age (years), median (range) & $57(21-93)$ & $52(24-97)$ & 0.954 \\
\hline Male, $\mathrm{n}(\%)$ & $19(82.6)$ & $55(65.5)$ & 0.115 \\
\hline Weight, kg, mean (SD) & $83.22(15.3)$ & $77.61(11.58)$ & 0.781 \\
\hline BMI, mean (SD) & $31.22(6.25)$ & $28.54(6.1)$ & 0.653 \\
\hline \multicolumn{4}{|l|}{ Nationality, n (\%) } \\
\hline Saudi & $22(95.65)$ & $66(78.57)$ & 0.068 \\
\hline \multicolumn{4}{|l|}{ Residence (city, region), n (\%) } \\
\hline Hofuf, Al-Ahsa & $16(69.56)$ & $50(59.52)$ & 0.286 \\
\hline Mubbarraz, Al-Ahsa & $7(30.44)$ & $34(40.48)$ & 0.172 \\
\hline \multicolumn{4}{|l|}{ Educational level, n (\%) } \\
\hline Illiterate & $6(26.09)$ & $19(22.62)$ & 0.754 \\
\hline Primary to secondary & $14(60.87)$ & 54 (64.29) & 0.468 \\
\hline University & $3(13.05)$ & $11(13.09)$ & 0.566 \\
\hline \multicolumn{4}{|l|}{ Occupation, n (\%) } \\
\hline Healthcare worker & $0(0)$ & $19(22.62)$ & $0.011^{*}$ \\
\hline Non-healthcare worker & $23(100)$ & $65(77.38)$ & $0.012^{*}$ \\
\hline
\end{tabular}

Data are number (\%) unless otherwise indicated. Abbreviations: BMI, body mass index; n/a, not applicable; $S D$, standard deviation. * Represents significant differences

Table 2: Comorbidities and symptoms of confirmed MERS-CoV cases based on mode of virus transmission

\begin{tabular}{|c|c|c|c|}
\hline Variable & $\begin{array}{l}\text { Animal-to-human group } \\
\text { (primary infection) }(n=23)\end{array}$ & $\begin{array}{l}\text { Human-to-human group } \\
\text { (secondary infection) }(n=84)\end{array}$ & $\begin{array}{c}P- \\
\text { value }\end{array}$ \\
\hline \multicolumn{4}{|l|}{ Comorbidities, $n(\%)$} \\
\hline Chronic kidney disease & $3(13.04)$ & $18(21.43)$ & 0.555 \\
\hline Chronic heart disease & $6(26.09)$ & $27(32.14)$ & 0.370 \\
\hline Chronic lung disease & $2(8.69)$ & $7(8.33)$ & 0.456 \\
\hline Liver disease & $0(0)$ & $9(10.71)$ & 0.200 \\
\hline Diabetes & $14(60.86)$ & $38(45.23)$ & 0.815 \\
\hline Hypertension & $3(13.04)$ & $34(40.47)$ & $0.007^{*}$ \\
\hline Malignancy & $1(4.34)$ & $2(2.38)$ & 0.520 \\
\hline Obesity & $11(47.82)$ & $37(44.04)$ & 0.802 \\
\hline Smoking & $2(8.68)$ & $15(17.85)$ & 0.355 \\
\hline Immunosuppressive therapies use & $5(21.73)$ & $23(27.38)$ & 0.790 \\
\hline Immunocompromised status & $3(13.04)$ & $7(8.33)$ & 0.445 \\
\hline Organ transplant & $0(0)$ & $6(7.14)$ & 0.337 \\
\hline Pregnant & $0(0)$ & $3(3.57)$ & 0.358 \\
\hline \multicolumn{4}{|l|}{ Symptoms, $n(\%)$} \\
\hline Onset to admission, $\mathrm{d}$, median (range) & $4.1(2-7)$ & $6.6(4-16)$ & $\mathrm{n} / \mathrm{a}$ \\
\hline Fever & $14(60.86)$ & $64(76.18)$ & 0.809 \\
\hline Cough & $9(39.13)$ & $56(66.66)$ & 0.240 \\
\hline Shortness of breath & $8(34.78)$ & $34(40.46)$ & 0.810 \\
\hline Myalgias & $2(8.69)$ & $7(8.33)$ & 0.956 \\
\hline Sore throat & $5(21.73)$ & $14(16.66)$ & 0.532 \\
\hline Haemoptysis & $3(13.04)$ & $11(13.09)$ & 0.995 \\
\hline Anorexia & $0(0)$ & $6(7.14)$ & 0.337 \\
\hline Nausea & $6(26.08)$ & $13(15.47)$ & 0.235 \\
\hline Vomiting & $4(17.39)$ & $18(21.42)$ & 0.778 \\
\hline Diarrhoea & $7(30.43)$ & $26(30.95)$ & 0.962 \\
\hline Headache & $4(17.39)$ & $22(26.19)$ & 0.423 \\
\hline Abdominal pain & $3(13.04)$ & $13(15.47)$ & 0.879 \\
\hline Confusion & $2(8.69)$ & $13(15.47)$ & 0.517 \\
\hline Hypoxia, O2 saturation <95\% & $11(47.82)$ & $36(42.85)$ & 0.813 \\
\hline Abnormal chest radiograph & $16(69.56)$ & $44(52.38)$ & 0.162 \\
\hline
\end{tabular}

Data are number (\%) unless otherwise indicated. Abbreviations: n/a, not applicable. * Represents significant differences

Hypertension was the only statistically significant comorbidity between the two groups $(13.04 \%$ for animal-to-human group vs $40.47 \%$ for human-tohuman group, $p=0.007$ ) (Table 2). Three (3.57
$\%$ ) of the 84 cases in the human-to-human transmission group were pregnant women. One of these women died; she was 37 years of age (gravida 2, para 1, 29 weeks gestation), and had 
a history of underlying medical conditions. Acute kidney injury was the only statistically significant MERS-CoV-associated complication between the two groups $(39.13 \%$ for animal-to-human group vs $15.47 \%$ for human-to-human group, $p=$ $0.020)$.

Laboratory findings did not differ statistically between the two groups. Leukopenia, lymphopenia, thrombocytopenia, elevated AST, and elevated LDH were not much different in both groups (Table 3). On admission, animal-tohuman group had less lymphocytosis than the human-to-human group (0\% vs $14.28 \%, p=$ 0.071). Animal-to-human group had elevated ALT (> $55 \mathrm{IU} / \mathrm{L}$ ) more than human-to-human group $(26.08 \%$ vs $10.71 \%, p=0.087)$.

Compared with the patients in the animal-tohuman transmission group, a greater percentage of patients in the human-to-human group transmission group experienced sepsis and septic shock ( $17.39 \%$ vs $26.19 \%$ and $13.04 \%$ vs $20.23 \%$, respectively; Table 4 ).

Compared with the animal-to-human transmission group, the median values for the APACHE II and SOFA scores were greater in the human-to-human transmission group (median APACHE II, 11.2 vs 23 , respectively; median SOFA, 10.9 vs 12.55, respectively). The difference between the APACHE II scores was statistically significant $(p=0.043)$. The animal-to- human transmission group had better treatment outcomes in terms of recovery, discharge, and death. Compared with the patients in the animalto-human transmission group, more patients in the human-to-human transmission group were admitted to the ICU (43.47 \% vs $51.19 \%$, respectively). For the group of patients infected via animal-to-human transmission, the median time from the onset of symptoms of infection to ICU admission was 8 days compared with 4 days in the group of patients infected via human-tohuman transmission $(p=0.041)$. The time from onset of symptoms to the initiation of mechanical ventilation was longer in the animal-to-human transmission group compared with the human-tohuman transmission group (median time, 6 days (range, $4-8$ days) vs 4 days (range, $2-10$ days), respectively). Compared with the patients in the animal-to-human transmission group, the patients in the human-to-human transmission group required more time to respond to antiviral treatment (median time, 5 days (range, $4-9$ days) vs 11 days (range, 7 - 13 days), respectively). MERS-CoV infections resolved more quickly in the patients infected via animalto-human transmission compared with those infected via human-to-human transmission (median time, 7 days (range, $4-8$ days) vs 13 days (range, $8-17$ days), respectively). The median times from onset of symptoms to death were 11 days for the patients infected via contact with animals and 5 days for the patients infected via contact with humans $(p=0.048)$.

Table 3: Laboratory findings and screening for microbial coinfections and use of antibacterials and antiviral agents of confirmed MERS-CoV cases based on mode of virus transmission

\begin{tabular}{|c|c|c|c|}
\hline Variable & $\begin{array}{l}\text { Animal-to-human group } \\
\text { (primary infection) }(n=23)\end{array}$ & $\begin{array}{l}\text { Human-to-human group } \\
\text { (secondary infection) } \\
\text { ( } \mathrm{n}=84)\end{array}$ & $\begin{array}{c}P- \\
\text { value }\end{array}$ \\
\hline \multicolumn{4}{|l|}{ Laboratory findings, $n$ (\%) } \\
\hline Leukopenia (<4.0 x 109 cells/L) & $3(13.04)$ & 16 (19.04) & 0.772 \\
\hline Lymphopenia (<1.5 x 109 cells/L) & 7 (30.43) & $25(29.76)$ & 0.950 \\
\hline Lymphocytosis (> 4.0 x 109 cells/L) & $0(0)$ & $12(14.28)$ & 0.071 \\
\hline Thrombocytopenia (<140 x 109 cells/L) & $7(30.43)$ & 28 (33.33) & 0.793 \\
\hline Elevated AST (> $40 \mathrm{IU} / \mathrm{L})$ & $4(17.39)$ & $12(14.28)$ & 0.744 \\
\hline Elevated ALT (> 55 IU/L) & $6(26.08)$ & $9(10.71)$ & 0.087 \\
\hline Elevated LDH (> 190 IU/L) & $5(21.73)$ & $23(27.38)$ & 0.790 \\
\hline $\begin{array}{l}\text { Blood culture or respiratory-tract samples } \\
\text { screened for bacterial, viral or fungal } \\
\text { pathogens, } n(\%)\end{array}$ & $8(34.78)$ & $19(22.61)$ & 0.280 \\
\hline $\begin{array}{l}\text { Positive cases for bacterial, viral or fungal } \\
\text { pathogens, } n(\%)\end{array}$ & $5(21.73)$ & $12(14.28)$ & 0.519 \\
\hline Concomitant Bacterial infections, n (\%) & $2(40)$ & $7(58.33)$ & 0.956 \\
\hline Concomitant Viral infections, $\mathrm{n}(\%)$ & $2(40)$ & $3(25)$ & 0.292 \\
\hline Concomitant Fungal infections, $\mathrm{n}(\%)$ & $1(20)$ & $2(16.66)$ & 0.520 \\
\hline Charted on antibacterials, $\mathrm{n}(\%)$ & $8(34.78)$ & $19(22.61)$ & 0.280 \\
\hline Charted on antiviral agents, $\mathrm{n}(\%)$ & $6(26.08)$ & 29 (34.52) & 0.617 \\
\hline
\end{tabular}

Data are number (\%) unless otherwise indicated. Abbreviations: ALT, alanine aminotransferase; AST, aspartate aminotransferase; IU/L, international unity per litre; $L D H$, lactate dehydrogenase; $n / a$, not applicable. * Represents significant differences 
Table 4: Complications, MERS-CoV infection severity and treatment outcomes of confirmed MERS-CoV cases based on mode of virus transmission

\begin{tabular}{|c|c|c|c|}
\hline Variable & $\begin{array}{l}\text { Animal-to-human } \\
\text { group (primary } \\
\text { infection) }(n=23)\end{array}$ & $\begin{array}{l}\text { Human-to-human } \\
\text { group (secondary } \\
\text { infection) }(\mathrm{n}=84)\end{array}$ & $P$-value \\
\hline \multicolumn{4}{|l|}{ Complications related to MERS-CoV infection, $n(\%)$} \\
\hline Pneumonia & $4(17.39)$ & $17(20.23)$ & 0.761 \\
\hline ARDS & $8(34.78)$ & $19(22.61)$ & 0.280 \\
\hline SARI & $1(4.34)$ & $6(7.14)$ & 0.631 \\
\hline AKI & $9(39.13)$ & $13(15.47)$ & $0.020^{*}$ \\
\hline Sepsis & $4(17.39)$ & $22(26.19)$ & 0.582 \\
\hline Septic shock & $3(13.04)$ & $17(20.23)$ & 0.555 \\
\hline DIC & $0(0)$ & $8(9.52)$ & 0.197 \\
\hline Pericarditis & $0(0)$ & $3(3.57)$ & 0.480 \\
\hline \multicolumn{4}{|l|}{ MERS-CoV infection severity } \\
\hline APACHE II score, median & $11.2(4-16.6)$ & $23(15.8-26.7)$ & $0.043^{*}$ \\
\hline SOFA score, median & $10.9(3.3-12)$ & $12.55(4-18.4)$ & 0.076 \\
\hline \multicolumn{4}{|l|}{ Treatment outcome, $n(\%)$} \\
\hline Recovered & $2(8.69)$ & $5(5.95)$ & 0.641 \\
\hline Transferred & $8(34.78)$ & $22(26.19)$ & 0.439 \\
\hline Died & $9(39.13)$ & $45(53.57)$ & 0.247 \\
\hline Discharged & $4(17.39)$ & $12(14.28)$ & 0.744 \\
\hline Patients admitted to the ICU, n (\%) & $10(43.47)$ & $43(51.19)$ & 0.630 \\
\hline $\begin{array}{l}\text { Time from MER-CoV infection onset of symptoms } \\
\text { to ICU admission, days, (median) }\end{array}$ & $8(3-14)$ & $4(3-11)$ & $0.041^{*}$ \\
\hline $\begin{array}{l}\text { Time from MER-CoV infection onset of symptoms } \\
\text { to the need of mechanical ventilation, days, } \\
\text { (median) }\end{array}$ & $6(4-8)$ & $4(2-10)$ & 0.257 \\
\hline $\begin{array}{l}\text { Time taken by MERS-CoV patient to respond to } \\
\text { antiviral treatment, days, (median) }\end{array}$ & $5(4-9)$ & $11(7-13)$ & 0.407 \\
\hline $\begin{array}{l}\text { Time taken by MERS-CoV patient to resolve, days, } \\
\text { (median) }\end{array}$ & $7(4-8)$ & $13(8-17)$ & 0.325 \\
\hline $\begin{array}{l}\text { Time from MER-CoV infection onset of symptoms } \\
\text { to death, days, (median) }\end{array}$ & $11(8-17)$ & $5(6-9)$ & $0.048^{*}$ \\
\hline
\end{tabular}

Table 5: Supportive measures offered to all patients during MERS-CoV infection, by mode of virus transmission

\begin{tabular}{lcrr}
\hline Variable & $\begin{array}{c}\text { Animal-to-human group } \\
\text { (primary infection) } \mathbf{( n = 2 3 )}\end{array}$ & $\begin{array}{c}\text { Human-to-human group } \\
\text { (secondary infection) }(\mathbf{n}=\mathbf{8 4})\end{array}$ & $\begin{array}{c}\boldsymbol{P} \text { - } \\
\text { value }\end{array}$ \\
\hline Mechanical ventilation & $13(56.52)$ & $43(51.19)$ & 0.814 \\
Extracorporeal membrane oxygenation & $7(30.43)$ & $39(46.42)$ & 0.235 \\
Corticosteroid therapy & $10(43.47)$ & $27(32.14)$ & 0.331 \\
Vasopressor therapy & $8(34.78)$ & $33(39.28)$ & 0.811 \\
Immunoglobulin therapy & $9(39.13)$ & $24(28.57)$ & 0.445 \\
Renal replacement therapy & $5(21.73)$ & $26(30.95)$ & 0.448 \\
Prone positioning & $4(17.39)$ & $25(29.76)$ & 0.422 \\
Packed red blood cell transfusion & $3(13.04)$ & $21(25)$ & 0.272 \\
Osteltamivir therapy & $2(8.69)$ & $11(13.09)$ & 0.730 \\
Number of antibacterial therapy agents & $3.2(1.1)$ & $2.4(0.6)$ & 0.201 \\
\hline
\end{tabular}

Data are number (\%) or mean (standard deviation)

The results for the supportive measures offered to patients during MERS-CoV infection based on mode of virus transmission are presented in Table 5. The patients infected via animal-tohuman transmission received greater numbers of antibacterial agents, compared with the patients in the other group (mean number of antimicrobial therapies (standard deviation), 3.2 (1.1) vs 2.4 (0.6), respectively, $p=0.201)$.
The results for the analysis of the antibacterial therapies used to treat MERS-CoV-associated bacterial pneumonia are presented in Table 6 . The between-group differences (animal-tohuman transmission vs human-to-human transmission) in the use of piperacillin and tazobactam plus levofloxacin (39.13 vs $17.85 \%$, $p=0.046$, respectively), levofloxacin alone (34.78 vs $13.09 \%, p=0.028$, respectively), and vancomycin plus levofloxacin (26.08 vs $8.33 \%$, 
respectively, $p=0.032$ ) were statistically significant.

The results for the analysis of the antiviral agents and other medications used to treat the patients are presented in Table 7. Significantly fewer patients in the animal-to-human transmission group compared with the human-to-human transmission group received ribavirin (34.78 vs $63.09 \%, p=0.019$, respectively), interferon- $\alpha 2 \mathrm{a}$ (17.39 vs $51.19 \%$, respectively, $p=0.004$ ), interferon- $\alpha 2 b \quad(21.73 \%$ vs $58.33 \%$, respectively, $p=0.002$ ), and lopinavir- ritonavir ( $17.39 \%$ vs $44.04 \%$, respectively, $p=0.028$ ).

\section{DISCUSSION}

We examined between-group differences in demographic characteristics, comorbidities, symptoms, laboratory findings, screening for microbial coinfections, use of antibacterials, antiviral agents and supportive measures, complications related to MERS-CoV infection, MERS-CoV infection severities, and treatment outcomes for 107 patients infected with MERSCoV via animal-to-human transmission or human-to-human transmission of the virus. Most of the patients in each group were citizens of Saudi Arabia $(95.65 \%$ and $78.57 \%$, respectively) and were from the Hofuf region (69.56 \% and $59.52 \%$, respectively) (Table 1). The area covered by the Hofuf region is larger than that covered by Mubbarraz; the Hofuf region includes relatively more and larger desert areas where camels are present. In general, many of the findings of this study confirm or contradict the findings of previous studies [15-21]. We identified a small sample of animal-to-human MERS-CoV cases that were similar to those examined in Cauchemez et a/s comprehensive analysis of the transmission modes associated with 681 MERS-CoV cases detected in Saudi Arabia between 2013 and 2014 [15]. Cauchemez and colleagues found that only $12 \%$ of cases were due to camel exposure; the remaining cases of infection were due to human-to-human transmission.

Table 6: Antibacterial agents used to treat bacterial pneumonia in patients with MERS-CoV infection, by mode of virus transmission

\begin{tabular}{|c|c|c|c|}
\hline Antibiotics administered & $\begin{array}{l}\text { Animal-to-human } \\
\text { group (primary } \\
\text { infection) }(n=23)\end{array}$ & $\begin{array}{l}\text { Human-to-human } \\
\text { group (secondary } \\
\text { infection) }(n=84)\end{array}$ & $P$-value \\
\hline Piperacillin and tazobactam plus levofloxacin & $9(39.13)$ & $15(17.85)$ & $0.046^{*}$ \\
\hline Levofloxacin alone & $8(34.78)$ & $11(13.09)$ & $0.028^{*}$ \\
\hline Vancomycin plus levofloxacin & $6(26.08)$ & $7(8.33)$ & $0.032^{*}$ \\
\hline Azithromycin plus cefotaxime & $6(26.08)$ & $11(13.09)$ & 0.194 \\
\hline Piperacillin and tazobactam plus azithromycin & $5(21.73)$ & $21(25)$ & 0.747 \\
\hline Levofloxacin plus aztreonam & $5(21.73)$ & $6(7.14)$ & 0.056 \\
\hline Ceftriaxone plus levofloxacin & $4(17.39)$ & $9(10.71)$ & 0.471 \\
\hline Levofloxacin plus gentamycin & $4(17.39)$ & $8(9.52)$ & 0.238 \\
\hline Linezolid plus moxifloxacin & $3(13.04)$ & $4(4.76)$ & 0.168 \\
\hline Azithromycin plus ceftriaxone & $3(13.04)$ & $13(15.47)$ & 0.772 \\
\hline Levofloxacin plus ertapenem & $3(13.04)$ & $2(2.38)$ & 0.065 \\
\hline Moxifloxacin alone & $3(13.04)$ & $7(8.33)$ & 0.445 \\
\hline Vancomycin plus imipenem plus ciprofloxacin & $1(4.34)$ & $0(0)$ & 0.215 \\
\hline Imipenem plus levofloxacin & $1(4.34)$ & $9(10.71)$ & 0.686 \\
\hline $\begin{array}{l}\text { Vancomycin plus piperacillin and tazobactam plus } \\
\text { moxifloxacin }\end{array}$ & $1(4.34)$ & $5(5.95)$ & 0.767 \\
\hline
\end{tabular}

Data are number (\%). *Represents significant differences

Table 7: Antiviral agents and other medications used in all cases to fight MERS-CoV infection based on mode of virus transmission

\begin{tabular}{|c|c|c|c|}
\hline Medication & $\begin{array}{l}\text { Animal-to-human group } \\
\text { (primary infection) }(n=23)\end{array}$ & $\begin{array}{c}\text { Human-to-human group } \\
\text { (secondary infection) }(n=84)\end{array}$ & $P$-values ${ }^{\text {a }}$ \\
\hline Ribavirin & $8(34.78)$ & $53(63.09)$ & $0.019^{*}$ \\
\hline Interferon- $\alpha 2 a$ & $4(17.39)$ & $43(51.19)$ & $0.004^{*}$ \\
\hline Interferon- $\alpha 2 b$ & $5(21.73)$ & 49 (58.33) & $0.002^{*}$ \\
\hline Interferon- $\beta 1 \mathrm{a}$ & $7(30.43)$ & $41(48.80)$ & 0.162 \\
\hline Lopinavir- ritonavir & $4(17.39)$ & 37 (44.04) & $0.028^{*}$ \\
\hline Glucocorticoids & $3(13.04)$ & $21(25)$ & 0.392 \\
\hline Mycophenolate mofetil & $4(17.39)$ & $18(21.42)$ & 0.761 \\
\hline Convalescent plasma & $2(8.69)$ & $12(14.28)$ & 0.730 \\
\hline
\end{tabular}


In our study, $21.4 \%$ of the patients had a history of exposure to animals; this difference was likely due to the longer study timeline (i.e., > 4 years). A significant percentage of the cases of infection were patients with histories of exposure in healthcare settings $(22.62 \%, p=0.011$, Table $1)$. These patients were likely infected as a result of systemic weaknesses in infection control procedures. Most patients in both groups had underlying comorbidities (e.g., hypertension, diabetes mellitus, obesity, chronic kidney disease, chronic cardiac disease, and use of immunosuppressive therapies. The high rates of comorbidities support the findings from a study by Assiri and colleagues [16].

Three pregnant MERS-CoV patients who all required ICU care were identified (Table 2). One of these patients died, which was consistent with the results of studies that indicate that MERSCoV infection is associated with serious health risks to mothers and infants during pregnancy [17].

At admission, the symptoms in both groups in both groups of patients were almost equivalent; no patients in the animal-to-human transmission group had anorexia at admission (0\% vs 7.14 $\%)$, and more of these patients reported that they were nauseous (26.08 \% vs $15.47 \%)$. The patients in the animal-to-human transmission group were less likely to have leukopenia and lymphocytosis, compared with the patients in the human-to-human transmission group (13.04\% vs $19.04 \%$ and $0 \%$ vs $14.28 \%$, respectively); they were also more likely to have elevated serum alanine aminotransferase concentrations (26.08 \% vs $10.71 \%$, respectively). However, these parameters have poor power to differentiate between modes of virus transmission.

Patients in both groups were vulnerable to concomitant infections, especially bacterial and viral infections [18]. This susceptibility to coinfections indicates the importance of infection prevention measures. Concomitant infection is a predictor of severe MERS-CoV illness [19]. The World Health Organization found that the mortality rate from MERS-CoV infection is $35 \%$ (720 / 2066 patients) [20]. Cauchemez et al found that the mortality rate of patients infected via the primary route is $74 \%$ (14 / 19 patients; detected through routine surveillance), compared with $21 \%$ (5 / 24 patients) for those infected via human-to-human transmission [21]. We found very different rates of mortality based on mode of MERS-CoV transmission (39.13\% mortality rate in the animal-to-human transmission group compared with $53.57 \%$ in the human-to-human transmission group). The mortality rate reported by $\mathrm{WHO}$ is less than the rate in our study population. The mortality rates in our study population were also different from those found by Cauchemez et al. We evaluated more severe cases and detected fewer individuals with mild symptoms. Our mortality rate estimates might therefore be overestimates and affected by study bias. The older ages of the patients and the preexisting comorbidities are risk factors for death from MERS-CoV infection [16,22]. The greater case-mortality rate in the human-to-human transmission group might also be associated with the higher APACHEE II and SOFA scores and the higher rates of sepsis and septic shock. The more severe MERS-CoV infections in the human-to-human transmission group resulted in a relatively higher ICU admission rate, a shorter time from onset of symptoms to ICU admission and to need for mechanical ventilation, a longer time to respond to antiviral treatment and resolve the infection, and a shorter time from onset of symptoms to death (Table 4).

Lack of a defined optimal management plan for MERS-CoV disease results in the use of various treatment options and adjuvant therapies during a hospital stay. Supportive measures included prevention of secondary infections, respiratory support, circulatory support, and preservation of renal, hepatic, and neurological function. In addition to implementation of the basic principles of critical care medicine, immunotherapies are used to treat MERS-CoV disease. The frequencies of the supportive measures used for both groups were similar, but no conclusions can be made about efficacy. Glucocorticoids and immunoglobulins were used extensively to treat the patients in both groups even though they are not recommended for treatment of MERS-CoV infection; results of studies suggest they are ineffective and unsafe [23].

The greater number of antibacterial agents used to treat the patients in the animal-to-human transmission group was likely due to the higher percentage of concomitant infections. In contrast with the high frequency of antibiotic use in the animal-to-human transmission group, antiviral agents were used more often in the human-tohuman transmission group. This difference may be due to greater suspicion of viral infection or higher case-severity. Taken together, the results suggested that the unfavourable treatment outcomes in the patients in the human-to-human transmission group could be attributed to older age, presence of comorbidities, and delays in treatment initiation. 


\section{Limitations of the study}

This study had some limitations. First, the retrospective study design could have introduced potential reporting bias due to reliance on clinical case records. Second, the small sample size of the animal-to-human transmission group might have reduced the study power and negatively affected the ability to detect statistically significant between-group differences. Third, we were only able to identify MERS-CoV cases who were infected via contact with the primary animal host (camel) and not via contact with another mammal (e.g., bat, rabbit, or horse). Finally, some follow-up data were unavailable. Clinical follow-up data for patients after recovery from MERS-CoV infection could be used to examine longer-term functional and psychological abnormalities.

\section{CONCLUSION}

MERS-CoV transmitted from human-to-human was more virulent, required more ICU treatment, and was associated with a higher case-mortality rate. The relatively higher use of antiviral agents could have been due to a greater suspicion of viral infection or a higher case-severity. The poorer treatment outcomes could be attributed to older age, presence of comorbidities, and delays in treatment initiation. In contrast, MERS-CoV transmitted from animal-to-human caused less case-fatality and required more antibacterial therapies. The higher number of antibacterial agents used for the patients in the animal-tohuman transmission group was likely due to the higher percentage of concomitant infections.

\section{DECLARATIONS}

\section{Acknowledgement}

The authors would like to acknowledge the Ministry of Health and the Director of the Directorate of Health Affairs in Alhassa for supporting this research. We also would like to extend our thanks to King Fahad Hofuf Hospital for participating in this study.

\section{Conflict of interest}

No conflict of interest associated with this work.

\section{Contributions of authors}

We declare that this work was performed by the authors named in this article and all liabilities pertaining to claims relating to the content of this article will be borne by the authors. S.A., M.T., M.A., and A.A. contributed to the design and implementation of the research, to the analysis of the results, and to the preparation of the manuscript. F.A, J.A., and A.A. verified the analytical methods and performed the computations. S.A. and J.A. supervised the data collection. All authors discussed the results and contributed to the final manuscript. All authors read and approved the manuscript for publication.

\section{REFERENCES}

1. Zaki AM, Van Boheemen S, Bestebroer TM, Osterhaus $A D$, Fouchier RA. Isolation of a novel coronavirus from a man with pneumonia in Saudi Arabia. N Engl J Med 2012; 367(19): 1814-1820.

2. World Health Organization. Middle East respiratory syndrome coronavirus (MERS-CoV) [cited 2015 Dec 6]. Available from: http://www.who.int/emergencies/merscoven.

3. Ministry of Health: Saudi Arabia. Command \& Control Center: statistics [cited 2015 Dec 6]. Available from: http://www.moh.gov.sa/en/CCC/PressReleases/Pages/d efault.aspx.

4. Guery B, Poissy J, el Mansouf L, Séjourné C, Ettahar N, Lemaire X, Vuotto $F$, Goffard A, Behillil S, Enouf $V$, et al. Clinical features and viral diagnosis of two cases of infection with Middle East Respiratory Syndrome coronavirus: a report of nosocomial transmission. Lancet 2013; 381(9885): 2265-2272.

5. Assiri A, McGeer A, Perl TM, Price CS, Al Rabeeah AA, Cummings DA, Alabdullatif ZN, Assad M, Almulhim A, Makhdoom $\mathrm{H}$, et al. Hospital outbreak of Middle East respiratory syndrome coronavirus. N Engl J Med 2013; 369(5): 407-416.

6. Wang $Q$, Qi J, Yuan $Y$, Xuan $Y$, Han $P$, Wan $Y$, Ji W, Li $Y$, Wu Y, Wang J, et al. Bat origins of MERS-CoV supported by bat coronavirus HKU4 usage of human receptor CD26. Cell Host Microbe 2014; 16(3): 328-337.

7. Khalafalla $A l, L u X$, Al-Mubarak Al, Dalab AH, AlBusadah KA, Erdman DD. MERS-CoV in Upper Respiratory Tract and Lungs of Dromedary Camels, Saudi Arabia, 2013-2014. Emerg Infect Dis 2015; 21(7): 1153-1158.

8. Memish ZA, Cotten M, Meyer B, Watson SJ, Alsahafi AJ, Al Rabeeah AA, Corman VM, Sieberg A, Makhdoom $H Q$, Assiri $A$, et al. Human infection with MERS coronavirus after exposure to infected camels, Saudi Arabia, 2013. Emerg Infect Dis 2014; 20(6): 1012.

9. Gulland A. Two cases of novel coronavirus are confirmed in France. BMJ 2013; 346: $\mathbf{f 3 1 1 4 .}$

10. Madani TA. Case definition and management of patients with MERS coronavirus in Saudi Arabia. Lancet Infect Dis 2014; 14(10): 911-913.

11. World Health Organization. Middle East respiratory syndrome coronavirus (MERS-CoV). Update on MERS- 
CoV transmission from animals to humans, and interim recommendations for at-risk groups [cited 2017 Sep 10]. Available from: http://www.who.int/csr/disease/coronavirus_infections/M ERS_CoV_RA_20140613.pdf?ua=1.

12. Centers for Disease Control and Prevention. Interim guidance for healthcare professionals. Patients in the U.S. who should be evaluated for MERS-CoV infection [cited 2017 Sep 10]. Available from: http://www.cdc.gov/coronavirus/mers/interimguidance.html.

13. Who Mers-Cov Research Group. State of knowledge and data gaps of Middle East respiratory syndrome coronavirus (MERS-CoV) in humans. PLoS Curr 2013; 5.

14. Association WM. World Medical Association Declaration of Helsinki. Ethical principles for medical research involving human subjects. Bull World Health Organ, 2001. 79 (4): 373. 15. Cauchemez S, Nouvellet P, Cori A, Jombart T, Garske T, Clapham H, Moore S, Mills HL, Salje $H$, Collins $C$, et al. Unraveling the drivers of MERS-CoV transmission. Proc Natl Acad Sci U S A 2016; 113(32): 9081-9086.

15. Assiri A, Al-Tawfiq JA, Al-Rabeeah AA, Al-Rabiah FA, AlHajjar S, Al-Barrak A, Flemban H, Al-Nassir WN, Balkhy $\mathrm{HH}$, Al-Hakeem RF, et al. Epidemiological, demographic, and clinical characteristics of 47 cases of Middle East respiratory syndrome coronavirus disease from Saudi Arabia: a descriptive study. Lancet Infect Dis 2013; 13(9): 752-761.
16. Assiri A, Abedi GR, Al Masri M, Bin Saeed A, Gerber SI, Watson JT. Middle east respiratory syndrome coronavirus infection during pregnancy: a report of 5 cases from Saudi Arabia. Clin Infect Dis 2016; 63(7): 951-953.

17. Zumla A, Hui DS, Perlman S. Middle East respiratory syndrome. Lancet 2015; 386(9997): 995-1007.

18. Saad M, Omrani AS, Baig K, Bahloul A, Elzein F, Matin MA, Selim MA, Al Nakhli D, Al Aidaroos AY, Al Sherbeeni $N$, et al. Clinical aspects and outcomes of 70 patients with Middle East respiratory syndrome coronavirus infection: a single-center experience in Saudi Arabia. Int J Infect Dis 2014; 29: 301-306.

19. World Health Organization. Middle East respiratory syndrome coronavirus (MERS-CoV) - Saudi Arabia [cited 2017 Sep 10]. Available from: http://www.who.int/csr/don/17-august-2017-mers-saudiarabia/en.

20. Cauchemez S, Fraser C, Van Kerkhove MD, Donnelly $C A$, Riley $S$, Rambaut $A$, Enouf $V$, van der Werf $S$, Ferguson NM. Middle East respiratory syndrome coronavirus: quantification of the extent of the epidemic, surveillance biases, and transmissibility. Lancet Infect Dis 2014; 14(1): 50-56.

21. Majumder MS, Kluberg SA, Mekaru SR, Brownstein JS. Mortality risk factors for Middle East respiratory syndrome outbreak, South Korea, 2015. Emerg Infect Dis 2015; 21(11): 2088-2090.

22. Stockman LJ, Bellamy R, Garner P. SARS: systematic review of treatment effects. PLoS Med 2006; 3(9): e343. 